\title{
EFECTO RESIDUAL DE INTERCALAR LEGUMINOSAS SOBRE EL RENDIMIENTO DE MAÍZ (Zea mays L.) EN NUEVE LOCALIDADES DE CENTRO AMÉRICA*
}

\author{
José Luis Zea**
}

\begin{abstract}
RESUMEN
Nueve ensayos para evaluar los efectos residuales de las siembras de leguminosas intercaladas en maíz fueron conducidos durante 1990 y 1991 en igual número de localidades de Centro América. El primer ciclo se evaluó en 1989 y 1990, años en los que se sembraron tres leguminosas a dosis de $20 \mathrm{y}$ $40 \mathrm{~kg} / \mathrm{ha}$ cada una. La materia seca de las leguminosas se dejó en sus respectivas parcelas al final del primer ciclo y en el año siguiente se sembró maíz en las mismas posturas que el ciclo anterior, teniéndose debidamente identificadas las parcelas. En este ciclo residual no se aplicó fertilizante a ningún tratamiento. Los resultados muestran que las leguminosas incrementaron el rendimiento de maíz en el ciclo residual, aunque sólo Canavalia ensiformis demostró tener un efecto neto positivo después de los dos ciclos. Este efecto neto fue de $203 \pm 314 \mathrm{Kg} / \mathrm{ha}$, en promedio de las nueve localidades.
\end{abstract}

\begin{abstract}
Residual effect of legume intercroping on corn (Zea mays L.) yield in nine localities in Central America. Nine trials were conducted, in like number of localities in Central America in 1990 and 1991, to evaluate the effect of legume intercropping on corn yield. The first cycle was evaluated in 1989 and 1990 , when trhree legumes were planted with doses of 20 and $40 \mathrm{~kg}$ of $\mathrm{P} /$ ha each, The legumes stubble was left on their respective plots at the end of the first cycle and in following year, corn was planted on the same plots as the preeeding eycle, keeping them well identified. No fertilizer was applied to any treatment in this residual cycle.
\end{abstract}

The results show that the legumes increased the corn yield in the residual cycle, although only Canavalia ensiformis showed to have a net positive effeet after the two cycles. This net effect is of $203 \pm 314 \mathrm{~kg} / \mathrm{ha}$ as an average of the nine localities.

\section{INTRODUCCIÓN}

Las leguminosas se han utilizado mucho como los cultivos más apropiados para mantenimiento y mejoramiento de los suelos agrícolas. Es bien conocida su capacidad para fijar nitrógeno.

Estudios de Mello (1978) muestran que la cantidad de este nutrimento en la materia seca de canavalia y mucuna eran de $3,51 \%$ y $2,78 \%$, respectivamente, y que la cantidad total fijada era de 190 y $157 \mathrm{~kg} \mathrm{~N} / \mathrm{ha}$. La National Academy of Sciences (1984) reporta que el follaje fresco de las leguminosas puede contener entre 0,5 y $1,0 \%$ de nitrógeno y que canavalia y mucuna pueden fijar hasta $200 \mathrm{Kg} \mathrm{N} / \mathrm{ha}$, mientras que vigna fija unos 80 .
Experimentos realizados en Brazil por la red TROPSOILS (Universidad de Cornell, 1990) incluyeron entre otras leguminosas a los dos mencionados arriba. En este estudio, las leguminosas se agregaron como materia seca al suelo, evaluándose su efccto en un primer ciclo de maíz bajo riego y luego durante un segundo ciclo en época húmeda, para evaluar residualidad. Los resultados obtenidos demuestran que los rendimientos de maíz logrados con el nitrógeno aportado por estas leguminosas es similar, por lo menos en el primer ciclo, al obtcnido al agregar $200 \mathrm{~kg} \mathrm{~N} / \mathrm{ha}$ como urea.

Otro de los beneficios que se mencionan de las leguminosas es el de aumentar la retención de humedad del suelo al formar un mulch, situación muy importante

*Trabajo presentado en la XXXVIII Reunión Anual del PCCMCA Managua, Nicaragua, 23-27 de marzo de 1992.

** ICTA, Guatemala. Proyecto Colaborativo de Agronomía de los Programas Nacionales de Centro América y El Caribe y CIMMYT (PRM). 
para las regiones de Centro América en donde se presenta un período de escasa o nula precipitación pluvial (canícula), el cual generalmente ocurre durante la floración del maíz, provocando rendimientos bajos.

El proyecto de siembras intercaladas de leguminosas en maíz se viene ejecutando desde 1989. Durante el transcurso de los años, y de acuerdo con los resultados que se han ido obteniendo, la estructura de los ensayos ha variado. En los ensayos de 1990 sólo se evaluaron tres leguminosas: Stizolobiun deeringianum Bort (mucuna), Vigna unguiculata L. (vigna) y Canavalia ensiformis L. (canavalia), bajo dos niveles de fósforo (20 y $40 \mathrm{~kg} / \mathrm{ha})$.

En 1990 se sembraron 13 ensayos en Centro América. Como en años anteriores, la información que se obtuvo fue que en el primer ciclo las leguminosas reducen el rendimiento de maíz, independientemente de la leguminosa, aunque la reducción es variable para cada una. Esta tendencia es general para un total de 24 ensayos que se han conducido entre 1989 y 1990 a través de Centro América (Zea 1992).

Como poca información se ha generado sobre los efectos de las leguminosas en un segundo ciclo, en 7 de los 13 sitios de 1990 se realizaron siembras en 1991 para evaluar el efecto residual. La única información con que se contaba era la obtenida en dos ensayos en los que se evaluó un segundo ciclo (1990) en las localidades de Jutiapa y Cuyuta, Guatemala, información que se incluye en este documento, junto con la de los otros 7 ensayos.

Efectos sobre control de malezas han sido medidos en términos biológicos, pero no en términos económicos; tampoco se ha cuantificado el efecto sobre reducción de la erosión. Estos aspectos representan beneficios adicionales proporcionados por las leguminosas que es necesario estimar. Por esta razón, en la actualidad participan ya las disciplinas de Economía tanto de CIMMYT como de los programas nacionales en el análisis económico de estos ensayos.

El objetivo de estos ensayos era determinar el efecto que en un ciclo residual tienen las leguminosas sobre el rendimiento de maíz.

\section{MATERIALES Y METODOS}

Los ensayos se condujeron en las repúblicas de Guatemala (5 ensayos), El Salvador (3 ensayos) y Panamá (1 ensayo), en los años 1990 (2 ensayos) y 1991 (7 ensayos). Las localidades fueron: 1990: Jutiapa y Cuyuta (Guatemala); 1991: Jutiapa, Cuyuta y La Máquina (Guatemala), Opico, Ciudad Arce y Sacacoyo (El Salvador) y La Honda (Panamá).

Para la evaluación de residualidad, los ensayos se sembraron en forma superpuesta, es decir, se utilizó la aleatorización y el plano de campo del año anterior respectivo. De los 11 ensayos de 1989, dos sitios se dejaron marcados y aislados para sembrar maíz el año siguiente y de los 13 ensayos de 1990, siete sitios se dejaron para sembrar maíz en 1991 (algunos sitios incluso fueron cercados). La biomasa producida por cada leguminosa en el primer año permaneció en cada parcela y allí se dejó descomponer. Por lo tanto, los resultados que aquí se presentan corresponden a un segundo año de evaluación en el mismo sitio, y en ese segundo año no se sembraron leguminosas. Los resultados obtenidos en el primer ciclo de evaluación aparecen publicados en el volumen 3 de Agronomía Mesoamericana (1992).

La siembra de maíz se efectuó en las mismas posturas en donde se sembró el primer año. Todos los ensayos se establecieron bajo labranza de conservación. En 1991 no se fertilizó con nitrógeno ni fósforo y en 1990 sólo se aplicaron $50 \mathrm{~kg} \mathrm{~N} / \mathrm{ha}$ en la localidad de Jutiapa. Al no fertilizar, las diferencias que se produjeran entre tratamientos con leguminosas versus testigos sin leguminosas hipotéticamente serían un efecto de la leguminosa sembrada el año anterior. El control de malezas se efectuó por métodos químico y manual, cuando fue necesario. Los materiales de maíz utilizados fueron siempre variedades mejoradas o híbridos recomendados por los programas nacionales. Los tratamientos y el diseño experimental fueron los mismos del primer año, por ser una evaluación de residualidad. El diseño fue bloques completos al azar, con tres repeticiones. Los factores en estudio fueron tres leguminosas y dos dosis de P. El listado de tratamientos aparece en el cuadro 1 . El efecto residual de tratamientos se determinó mediante el rendimiento de grano y de rastrojo de maíz.

Se efectuaron análisis de varianza para determinar el efecto de los factores leguminosas y dosis de fósforo. 
Para facilitar la interpretación de los resultados se realizaron comparaciones entre rendimiento promedio de tratamientos con leguminosas (promedio sobre dosis de P) versus testigos sin leguminosa y entre rendimientos obtenidos en 1990 y 1991.

\section{RESULTADOS Y DISCUSIÓN}

\section{Efecto residual de $P$}

En términos generales, la dosis de $\mathrm{P}$ no mostró efectos residuales significativos al realizar los análisis de varianza para rendimiento de grano y de rastrojo de maíz.

\section{Efecto sobre el rendimiento de grano}

En el cuadro 1 se presentan los rendimientos de grano de maíz obtenidos en las nueve localidades en las que se realizó la evaluación residual. El rendimiento de grano var ía entre 1226 y $2383 \mathrm{~kg} / \mathrm{ha}$, lo cual era de esperar, pues no se fertilizó con N y en 1991 la sequía afectó en toda Centro América.

Para determinar si en el segundo ciclo (residual) las leguminosas lograban compensar la reducción de rendimiento de grano de maíz producida en el primer ciclo se elaboró el cuadro 2 , en el que se presentan las diferencias de rendimiento de grano entre tratamientos

Cuadro 1. Medias de rendimiento de grano de mǻz $\mathrm{Kg} /$ ha y parámetros de precisión experimental. Ensayos residuales de leguminosas intercaladas, Centro América, 1991.

\begin{tabular}{|c|c|c|c|c|c|c|c|c|c|c|c|}
\hline \multirow[t]{3}{*}{ Tratamiento ${ }^{1}$} & \multicolumn{6}{|c|}{ Rendimiento ( $\mathrm{Kg} / \mathrm{ha})$} & \multirow{2}{*}{\multicolumn{3}{|c|}{ El Salvador }} & \multirow[b]{2}{*}{ Panamá } & \multirow{3}{*}{ Promedio } \\
\hline & \multicolumn{2}{|c|}{ Guatemala 90} & \multicolumn{4}{|c|}{ Guatemala 91} & & & & & \\
\hline & Jutiapa & Cuyuta & Jutiapa & Cuyuta & La & Máquina & Opico & Ciudad Arce & Sacacoyo & La Honda & \\
\hline Maíz + Sd 20P & 1856 & 1927 & 2502 & 1583 & & 1733 & 886 & 1763 & 1784 & 1173 & 1690 \\
\hline Maíz + Sd 40P & 1824 & 2535 & 2317 & 1640 & & 2161 & 968 & 1171 & 1519 & 1274 & 1712 \\
\hline Maíz + Vu 20P & 1924 & 816 & 2761 & 1193 & & 1890 & 1092 & 1635 & 1794 & 1067 & 1575 \\
\hline Maíz + Vu 40P & 1768 & 777 & 2495 & 1600 & & 1475 & 874 & 1497 & 1625 & 1432 & 1505 \\
\hline Maíz + Ce 20P & 1893 & 1253 & 2434 & 1667 & & 2020 & 1050 & 1135 & 2039 & 1162 & 1628 \\
\hline Maíz + Ce 40P & 1772 & 1650 & 2503 & 2627 & & 1822 & 883 & 1654 & 2042 & 1735 & 1854 \\
\hline Maíz solo 20P & 1188 & 1083 & 1910 & 1055 & & 1403 & 827 & 1289 & 1205 & 1233 & 1244 \\
\hline Maíz solo $40 P$ & 1562 & 644 & 2354 & 1460 & & 1627 & 943 & 1175 & 1035 & 729 & 1281 \\
\hline Promedio & 1768 & 1350 & 2383 & 1603 & & 1766 & 1242 & 1651 & 1780 & 1226 & \\
\hline Parámetros de & e Precisi & ón Expe & imental & & & & & & & & \\
\hline CME $\quad\left(t^{2} / h a^{2}\right)$ & 0,049 & 0,076 & 0,076 & 0,086 & & 0,123 & 0,059 & 0,171 & 0,152 & 0,123 & 0,192 \\
\hline GLE & 30 & 30 & 20 & 20 & & 21 & 20 & 20 & 20 & 22 & 19 \\
\hline Err Est Difer & $r \quad 0,181$ & 0,440 & 0,225 & 0,239 & & 0,282 & 0,198 & 0,337 & 0,316 & 0,286 & 0,357 \\
\hline
\end{tabular}

$\mathrm{Sd}=$ Stizolobium deeringianum; $V u=$ Vigna unguiculata $; \mathrm{Ce}=$ Canavalia ensiformis.

$20 \mathrm{P}-40 \mathrm{P}=$ dosis de fósforo en $\mathrm{kg} / \mathrm{ha}$.

La única localidad en la que se detectó efecto significativo de dosis de $\mathrm{P}$ fue en Cuyuta, con probabilidades de 0,0182 para rendimiento de grano y de 0,0162 para rendimiento de rastrojo. En ambos casos, la dosis de $40 \mathrm{~kg} / \mathrm{ha}$ es la que produce rendimientos más altos. La no respuesta estadística a dosis de $\mathrm{P}$ en el ciclo residual es similar a lo sucedido en el ciclo tratado (Zea 1992).

\section{Efecto residual de las leguminosas}

Basados en que la dosis de $\mathrm{P}$ no tiene efectos significativos y que las leguminosas son el factor más importante del estudio, los análisis del efecto de estas sobre el rendimiento de grano y rastrojo maíz se hicieron promediando a través de dosis de $\mathrm{P}$. con leguminosa versus testigo sin leguminosa obtenidas en 1990 y 1991.

Puede notarse que mucuna tiene un efecto neto neutro al cabo de los dos ciclos (compensa la pérdida de rendimiento ocacionada en el primer ciclo y produce una ganancia adicional no visible de $1 \mathrm{~kg} / \mathrm{ha}$, en promedio). Sin embargo, la inconsistencia o variabilidad de respuestas con esta leguminosa es muy grande (desviación estándar de $\pm 436 \mathrm{~kg} / \mathrm{ha}$ ), muy similar a lo que sucedió en el primer ciclo. En términos generales puede decirse que mucuna sólo logra compensar las pérdidas ocacionadas en el primer ciclo, pero al observar más detenidamente los datos del cuadro 2, esta leguminosa produce efectos netos positivos en 5 de las 9 localidades y negativos sólo en 4 . 
Cuadro 2. Efectos netos de leguminosas intercaladas sobre el rendimiento de grano de maíz a través de dos ciclos. Ensayos residuales de leguminosas intercaladas, Centro América, 1991.

\begin{tabular}{|c|c|c|c|c|}
\hline Localidad & $\begin{array}{l}\text { Trata- } \\
\text { miento }\end{array}$ & $\begin{array}{l}\text { Ciclo } \\
\text { Tratado } \\
(\mathrm{Kg} / \mathrm{ha})\end{array}$ & $\begin{array}{l}\text { Ciclo } \\
\text { Residual } \\
\text { (Kg/ha) }\end{array}$ & $\begin{array}{r}\text { Efecto neto } \\
\text { dos ciclos } \\
(\mathrm{Kg} / \mathrm{ha})\end{array}$ \\
\hline Jutiapa (1990) & $\begin{array}{l}\text { Maíz + Sd } \\
\text { Maíz + Vu } \\
\text { Maíz + Ce }\end{array}$ & $\begin{array}{l}-340 \\
-140 \\
-290\end{array}$ & $\begin{array}{l}465 \\
471 \\
458\end{array}$ & $\begin{array}{l}125 \\
331 \\
168\end{array}$ \\
\hline Cuyuta (1990) & $\begin{array}{l}\text { Maíz + Sd } \\
\text { Maíz + Vu } \\
\text { Maíz + Ce }\end{array}$ & $\begin{array}{r}-1490 \\
-390 \\
-480\end{array}$ & $\begin{array}{r}1367 \\
-68 \\
588\end{array}$ & $\begin{array}{r}-123 \\
-458 \\
108\end{array}$ \\
\hline Jutiapa & $\begin{array}{l}\text { Maíz + Sd } \\
\text { Maíz + Vu } \\
\text { Maíz + Ce }\end{array}$ & $\begin{array}{l}-240 \\
-440 \\
-215\end{array}$ & $\begin{array}{l}278 \\
496 \\
337\end{array}$ & $\begin{array}{r}38 \\
56 \\
122\end{array}$ \\
\hline Cuyuta & $\begin{array}{l}\text { Maíz + Sd } \\
\text { Maíz + Vu } \\
\text { Maíz + Ce }\end{array}$ & $\begin{array}{r}-1070 \\
-870 \\
-625\end{array}$ & $\begin{array}{l}354 \\
139 \\
890\end{array}$ & $\begin{array}{r}-716 \\
-731 \\
265\end{array}$ \\
\hline La Máquina & $\begin{array}{l}\text { Maíz + Sd } \\
\text { Maíz + Vu } \\
\text { Maíz + Ce }\end{array}$ & $\begin{array}{l}-450 \\
-860 \\
-320\end{array}$ & $\begin{array}{l}432 \\
168 \\
406\end{array}$ & $\begin{array}{r}-18 \\
-692 \\
86\end{array}$ \\
\hline Opico & $\begin{array}{l}\text { Maíz + Sd } \\
\text { Maíz + Vu } \\
\text { Maíz + Ce }\end{array}$ & $\begin{array}{r}-5 \\
-110 \\
-5\end{array}$ & $\begin{array}{l}42 \\
98 \\
82\end{array}$ & $\begin{array}{r}37 \\
-12 \\
77\end{array}$ \\
\hline Ciudad Arce & $\begin{array}{l}\text { Maíz + Sd } \\
\text { Maíz + Vu } \\
\text { Maíz + Ce }\end{array}$ & $\begin{array}{r}280 \\
-360 \\
-260\end{array}$ & $\begin{array}{l}235 \\
334 \\
163\end{array}$ & $\begin{array}{l}515 \\
-26 \\
-97\end{array}$ \\
\hline Sacacoyo & $\begin{array}{l}\text { Maíz + Sd } \\
\text { Maíz + Vu } \\
\text { Maíz + Ce }\end{array}$ & $\begin{array}{r}130 \\
-895 \\
80\end{array}$ & $\begin{array}{l}532 \\
590 \\
921\end{array}$ & $\begin{array}{r}662 \\
-305 \\
1001\end{array}$ \\
\hline La Honda & $\begin{array}{l}\text { Maíz + Sd } \\
\text { Maíz + Vu } \\
\text { Maíz + Ce }\end{array}$ & $\begin{array}{l}-760 \\
-370 \\
-365\end{array}$ & $\begin{array}{l}243 \\
269 \\
468\end{array}$ & $\begin{array}{r}-517 \\
-101 \\
103\end{array}$ \\
\hline Promedio & $\begin{array}{l}\text { Maíz + Sd } \\
\text { Maíz + Vu } \\
\text { Maíz + Ce }\end{array}$ & $\begin{array}{l}-438 \\
-493 \\
-276\end{array}$ & $\begin{array}{l}439 \\
277 \\
479\end{array}$ & $\begin{array}{r}1 \\
-216 \\
203\end{array}$ \\
\hline
\end{tabular}

En las localidades de El Salvador (Opico, Ciudad Arce y Sacacoyo), mucuna produce efecto neto positivo en las tres, siendo este efecto de $405 \mathrm{~kg} / \mathrm{ha}$, en promedio, superior al producido por canavalia, que es de $351 \mathrm{~kg} / \mathrm{ha}$. Los efectos netos producidos por esta leguminosa a través de las 9 localidades son afectados principalmente por localidades con mayor precipitación pluvial (Cuyuta, Guatemala, y La Honda, Panamá), localidades en las cuales se producen los efectos netos negativos más altos (-452 $\mathrm{kg} / \mathrm{ha}$, en promedio). Este efecto neto negativo también se debe en parte a que en 1989 no se le despuntó y su competencia con el maíz fue mayor (Jutiapa y
Cuyuta, 1990). Por las razones antes discutidas, esta leguminosa también puede ser de utilidad en ambientes similares a los evaluados, aunque necesite de manejo.

La única leguminosa que produjó un efecto neto negativo es la Vigna (no compensa la reducción del primer ciclo), el cual es fue $-216 \pm 357 \mathrm{~kg} / \mathrm{ha}$. Esto puede deberse a que por ser una leguminosa productora de grano, es más lo que extrae del suelo que lo que aporta y que, además, por su ciclo corto, seguramente la biomasa empieza a descomponerse en el primer ciclo, quedando muy poca para el ciclo residual.

Canavalia es la leguminosa que tiene un efecto neto positivo bien definido al cabo de los dos ciclos en ocho de las nueve localidades (89\%). En promedio, esta leguminosa produjó una ganancia neta de $203 \mathrm{~kg} / \mathrm{ha}$, con una desviación de $\pm 314 \mathrm{~kg} / \mathrm{ha}$.

La consistencia de efectos netos positivos de esta leguminosa a través de localidades está relacionada con los resultados del primer ciclo, en donde a través de 24 localidades de Centro América, se demostró que canavalia es la leguminosa que menos redujó el rendimiento de maíz y con la menor dispersión de datos (Zea 1992).

De acuerdo a como estaban planteados los ensayos, las ganancias obtenidas en el segundo ciclo (1991) hipotéticamente se deben a la aportación de las leguminosas. La cantidad de biomasa producida por ellas fue medida en 1990 en cuatro localidades, en dos de las cuales se realizó evaluación residual en 1991 (Jutiapa y Cuyuta, Guatemala). Las aportaciones de biomasa al suelo por las leguminosas, en promedio de las cuatro localidades fue de $1723 \mathrm{Kg} / \mathrm{ha}$ para mucuna, $3588 \mathrm{~kg} / \mathrm{ha}$ para vigna (promedio de tres localidades) y $5274 \mathrm{~kg} / \mathrm{ha}$ para canavalia. Estos datos pueden explicar en parte el por qué canavalia produjó los efectos netos positivos más altos al cabo de los dos ciclos de evaluación. Aunque vigna produce más biomasa que mucuna, por ser aquella de ciclo corto (unos 70 días a cosecha) la biomasa se empieza a descomponer en el primer ciclo, quedando poca para el ciclo residual.

\section{Efecto sobre rendimiento de rastrojo}

Datos de rendimiento de rastrojo se obtuvieron en seis localidades (3 de Guatemala y 3 de El Salvador) de las siete en las cuales se efectuó la evaluación residual en 1991. Los rendimientos medios obtenidos en esas seis 
localidades se presentan en el cuadro 3. Estos rendimientos variaron entre 1928 y $3401 \mathrm{~kg} / \mathrm{ha}$, siendo alrededor de un $50 \%$ más altos que los de grano.

Cuadro 3. Medias de rendimiento de rastrojo (materia seca) de maíz $\mathrm{Kg} / \mathrm{ha}$ y parámetros de precisión experimental. Ensayos residuales de leguminosas intercaladas, Centro América, 1991.

\begin{tabular}{|c|c|c|c|c|c|c|c|}
\hline \multirow[b]{2}{*}{ Tratamiento } & \multicolumn{7}{|c|}{ Rendimiento $(\mathrm{Kg} / \mathrm{ha})$} \\
\hline & $\begin{array}{c}\text { Jutia- } \\
\text { pa }\end{array}$ & Cuyu- & $\begin{array}{l}\text { La Ma- } \\
\text { quina }\end{array}$ & $=0$ & $\begin{array}{l}\text { Ciud. } \\
\text { Arce }\end{array}$ & $\begin{array}{l}\text { Saca- } \\
\text { coyo }\end{array}$ & $\begin{array}{l}\text { Pro- } \\
\text { med. }\end{array}$ \\
\hline $\begin{array}{l}\text { Maiz+Sd } 20 P \\
\text { Maiz+Sd } 40 P \\
\text { Maiz+Vu } 20 P \\
\text { Maiz+Vu } 40 P \\
\text { Maiz+Ce 20P } \\
\text { Maiz+Ce 40P } \\
\text { Maiz solo 2OP } \\
\text { Maiz solo 40P }\end{array}$ & $\begin{array}{l}3569 \\
3468 \\
3316 \\
3367 \\
3451 \\
3468 \\
2761 \\
2805\end{array}$ & $\begin{array}{l}2542 \\
2879 \\
2811 \\
2811 \\
2593 \\
4074 \\
2441 \\
2896\end{array}$ & $\begin{array}{l}2425 \\
2374 \\
2803 \\
2138 \\
2751 \\
2612 \\
2200 \\
2724\end{array}$ & $\begin{array}{l}2211 \\
2749 \\
2431 \\
2517 \\
2749 \\
2407 \\
2541 \\
2737\end{array}$ & $\begin{array}{l}3030 \\
2346 \\
2785 \\
2859 \\
2224 \\
2553 \\
2258 \\
2517\end{array}$ & $\begin{array}{l}2199 \\
1955 \\
1857 \\
1613 \\
2566 \\
2077 \\
1026 \\
1466\end{array}$ & $\begin{array}{l}2663 \\
2629 \\
2667 \\
2551 \\
2722 \\
2865 \\
2205 \\
2691\end{array}$ \\
\hline Promedio & 3401 & 2881 & 2503 & 2666 & 2716 & 1928 & \\
\hline $\begin{array}{l}\text { Parametros de } \\
\text { CME }\left(t^{2} / \mathrm{ha}^{2}\right) \\
\text { GLE } \\
\text { Err Est Dif }\end{array}$ & $\begin{array}{c}\text { Precisi } \\
0,185 \\
20 \\
0,351\end{array}$ & $\begin{array}{l}\text { on Exp } \\
0,254 \\
20 \\
0,412\end{array}$ & $\begin{array}{r}\text { eriment } \\
0,1970 \\
21 \\
0,3620\end{array}$ & $\begin{array}{l}\text { tal } \\
0,253 \\
20 \\
0,411\end{array}$ & $\begin{array}{r}0,115 \\
20 \\
0,277\end{array}$ & $\begin{array}{r}0,284 \\
20 \\
0,435\end{array}$ & $\begin{array}{r}0,215 \\
20 \\
0,378\end{array}$ \\
\hline
\end{tabular}

Los efectos sobre rendimiento de rastrojo son más difíciles de observar, aunque según los datos de las seis localidades, la tendencia general fue, en el primer ciclo (ciclo tratado), afectó negativo de las leguminosas en el rendimiento de rastrojo, efecto negativo que es variable por localidad y por leguminosa. En promedio de las seis localidades, la vigna es la que más redujo el rendimiento de rastrojo, con $450 \mathrm{~kg} / \mathrm{ha}$, mientras que canavalia lo redujo en $150 \mathrm{~kg} / \mathrm{ha}$ y mucuna no lo afectó. Esto último es explicable si se considera que en el año de 1990 a esta leguminosa se le dió manejo mediante despuntes durante el desarrollo del maíz, lo cual hace suponer que no compitió mucho con este.

De manera similar a como ocurrió con el rendimiento de grano, en el ciclo residual canavalia produjo la mayor ganancia $(350 \mathrm{Kg} / \mathrm{ha})$, logrando compensar la reducción del primer ciclo y produciendo un efecto neto al cabo de dos años de $200 \mathrm{~kg} / \mathrm{ha}$, efecto que cuantitativamente es igual al de mucuna, mientras que vigna no alcanzó a compensar la reducción ocacionada en el primer ciclo (efecto neto al cabo de dos ciclos de $-300 \mathrm{~kg} / \mathrm{ha}$ ).

Aunque no está del todo claro, el por qué las ganancias en rendimiento tanto de grano como de rastrojo producidas no son tan altas en relación a los testigos sin leguminosas puede explicarse con base a que bajo labranza de conservación la descomposición de la materia orgánica ocurre en forma más lenta, lo que afecta su capacidad para aportar nutrientes.

Adicional a lo que sucedió sobre el rendimiento, deben tenerse presente los beneficios dados por las leguminosas en relación al control de malezas, principalmente en el primer ciclo, así como la reducción de la erosión, aspectos que sólo se han cuantificado en términos físicos y se encuentran en proceso de análisis económico.

Finalmente, otras ventajas que tiene canavalia sobre mucuna, son: su hábito de crecimiento, no requiere de un manejo adicional en siembras intercaladas (lo cual implica un menor costo) y que por tener la capacidad de soportar sequía, ha mostrado que puede tolerar en el campo todo la época seca (noviembre a abril), logrando con ello reducir la erosión por viento y la ocasionada por las primeras lluvias, que son los más perjudiciales.

\section{CONCLUSIONES}

La evidencia de dos ciclos consecutivos de maíz (el primero intercado con leguminosas y el segundo en monocultivo) en nueve ensayos a través de Centro América demuestra que Canavalia ensiformis es una leguminosa que produce efectos netos positivos sobre el rendimiento de grano y rastrojo de maíz en forma consistente a través de ambientes. Sin embargo, para poder observar esta diferencia se hace necesario considerar al menos dos ciclos de cultivo, uno para el establecimiento de las leguminosas y el otro para la expresión de sus efectos.

\section{LITERATURA CITADA}

CORNELL UNIVERSITY. 1990. Green manures (documento en borrador). Preparado por el programa TROPSOILS, Universidad de Cornell, Ithaca, New York.

MELLO, F. 1978. N fixation by some legumes. Revista de Agricultura, Piracicaba, Brasil. Vol. 53, No. 1/2.

NATIONAL ACADEMY OF SCIENCES. 1984. Tropical legumes, Resources for the future. Washington,D.C. Pp. 292-332.

ZEA, J.L. 1992. Efecto de intercalar leguminosas con diferentes dosis de fósforo sobre el rendimiento de maíz, Zea mays L., en Centroamérica. Agronomía Mesoamericana, Alajuela [C.R.] 3:16-22. 